\title{
A análise de conteúdo como forma de tratamento dos dados numa pesquisa qualitativa em Educação Física escolar ${ }^{1}$
}

\author{
Marcílio Barbosa Mendonça de Souza Júnior* \\ Marcelo Soares Tavares de Melo** \\ Maria Eliete Santiago***
}

\begin{abstract}
Resumo: Muitas vezes, em livros e periódicos, se dá menor ênfase à elucidação da metodologia investigativa, favorecendo o não reconhecimento dos procedimentos e instrumentos de coleta e análise dos dados como construto da elaboração do pesquisador. Neste artigo, apresentamos uma reflexão acerca de uma das fases da metodologia científica, focalizando a análise de conteúdo categorial temática como uma das formas de tratamento dos dados. Tomamos como exemplo, para discutir e fundamentar 0 ato de pesquisa, uma investigação desenvolvida no âmbito da Educação Física escolar, na intenção de colaborarmos na consolidação da rigorosidade científica das pesquisas nessa área.
\end{abstract}

Palavras-chave: Metodologia científica. Pesquisa qualitativa. Análise de conteúdo. Educação Física escolar.

\footnotetext{
*Professor Doutor da Licenciatura da ESEF-UPE e do Mestrado Associado em Educação Física UPE/UFPB; Membro do Grupo de Estudos Etnográficos em Educação Física e Esportes (ETHNÓS) e Professor da FASNE. Recife, PE, Brasil. E-mail: m.souzajr@uol.com.br

"Professor Doutor Coordenador da Licenciatura da ESEF-UPE, Mestrado Associado em Educação Física UPE/UFPB e do Colégio de Aplicação da UFPE; Membro do ETHNÓS e Professor da FASNE. Recife, PE, Brasil. E-mail: mtavares19@hotmail.com

"***Professora Doutora do Programa de Pós-Graduação em Educação do CE/UFPE. Recife, PE, Brasil. E-mail: mesantiago@uol.com.br

${ }^{1}$ Este trabalho constitui parte da pesquisa realizada para elaboração de Tese de Doutorado, defendida no Programa de Pós-Graduação em Educação da Universidade Federal de Pernambuco (UFPE), na Linha de Pesquisa de Formação de Professores e Prática Pedagógica e ainda um dos recortes do Projeto de Pesquisa desenvolvido na Escola Superior de Educação Física da Universidade de Pernambuco (ESEF-UPE), sob o título Pesquisa em Educação Física Escolar, financiado pelo CNPq, por intermédio do Edital Universal - MCT/CNPq N ${ }^{\circ} 014 / 2008$. Tal projeto está vinculado à linda de pesquisa Prática Pedagógica e Formação Profissional em Educação Física do Programa Associado de Pós-Graduação em Educação Física - Mestrado UPE/UFPB.
} 


\section{INTRODUÇÃO}

A metodologia da pesquisa, na produção científica, constitui um dos elementos que confere aos estudos investigativos rigorosidade e reconhecimento perante o estatuto de Ciência. Porém, contraditoriamente, quando da socialização dos resultados dessas investigações, os fundamentos e procedimentos parecem não mais servir à comunidade acadêmica. Por vezes, as metodologias de pesquisa dos estudos científicos, quando se expressam numa publicação em formato de livros ou periódicos, são secundarizadas, isso quando não obscurecidas ou até mesmo negligenciadas, pois parece que o papel da metodologia da pesquisa só é compreendido como processo e não como produto da elaboração investigativa. Acreditamos que, por mais que a metodologia seja um caminho, uma estratégia, um percurso, numa pesquisa científica, esta se configura também como uma elaboração, por parte do pesquisador, na interação com o objeto de investigação e suas fontes de dados. Vemos, portanto, que se faz necessário refletirmos tanto acerca dos resultados e da discussão de dados de pesquisa quanto de sua trajetória de investigação.

Nossa reflexão acerca da análise de conteúdo, uma das formas de tratamento dos dados, se dá a partir da Perspectiva da Pesquisa Dialética na Educação, sob o foco da abordagem qualitativa, tomando como exemplo, para elucidar as dimensões operacionais do ato de pesquisa, uma investigação desenvolvida no âmbito da Educação Física escolar, que teve como objeto a constituição dos saberes escolares (SOUZA JÚNIOR, 2007), pelo olhar da Sociologia Crítica do Currículo (FORQUIN, 1993; GOODSON, 1995; MOREIRA, 1995; SILVA, 1999). Os fundamentos e procedimentos aqui expostos pautaram-se por uma pesquisa na literatura e no campo, com recorte empírico em Escolas da Rede Municipal de Ensino do Recife e tendo como fontes documentos pertinentes ao objeto e entrevistas com duas professoras ${ }^{2}$ de Educação Física (PEF1 e PEF2).

\footnotetext{
${ }^{2}$ Decidimos manter o feminino, quando nos referirmos aos sujeitos de pesquisa, para preservar sua identidade de gênero, ainda que isso, em virtude das características de nossa pesquisa, não tenha sido objeto de nenhuma reflexão.
} 


\section{ANÁLISE DE CONTEÚDO}

Partimos da compreensão de que uma pesquisa científica, numa abordagem qualitativa, é realizada num movimento contínuo de fases interligadas. No entanto, ainda que tais fases se imbriquem, numa dinâmica de idas e vindas, preservam-se, em cada uma dessas, características e objetivos singulares.

Segundo Minayo (1998), uma pesquisa passa por três fases: a) fase exploratória, na qual se amadurece o objeto de estudo e se delimita o problema de investigação; b) fase de coleta de dados, em que se recolhem informações que respondam ao problema; e c) fase de análise de dados, na qual se faz o tratamento, por inferências e interpretações, dos dados coletados.

No caso da pesquisa aqui situada, o objeto de estudo partiu da experiência do pesquisador com a formação inicial e continuada de professores de Educação Física, assim como de sua própria trajetória de formação. Percebia-se empiricamente que, reiteradamente, os professores de Educação Física se questionavam acerca da constituição dos saberes escolares, duvidando até da presença de conhecimentos estruturados nas aulas. Isso nos levou a indagar se os saberes escolares seriam constituídos da mesma forma entre as várias disciplinas do currículo, delimitando assim o problema de investigação.

Desse modo, entendemos que um conflito percebido na experiência prática, inclusive pessoal, pode se configurar num problema de investigação, mas não pode se confundir com esta, pois precisa amadurecer e enfrentar delimitações e recortes.

A partir de então foram definidos, com critérios coerentes com o objeto e o problema, o campo de pesquisa e os sujeitos para realizar a coleta de dados, por via de recolhimento de documentos e entrevistas. Após esta, os dados coletados passaram por um tratamento que ia desde a organização física até as interpretações. Se no início da pesquisa tínhamos projeções acerca das análises e no decorrer voltávamos ao objeto e problema, recorrentemente, no final recuperamos o contexto e questões de pesquisa para a realização das análises. 
A análise dos dados, ainda que não se dissocie das demais fases, tem como objetivo compreender o que foi coletado, confirmar ou não os pressupostos da pesquisa e ampliar a compreensão de contextos para além do que se pode verificar nas aparências do fenômeno.

Entre as diferentes e possíveis formas de análise de dados, destacamos aqui uma, a análise de conteúdo, que, comumente, tem sido utilizada nas pesquisas qualitativas em Educação Física escolar. Esta consiste num recurso técnico para análise de dados provenientes de mensagens escritas ou transcritas, no nosso caso, das mensagens vindas da literatura, dos documentos da rede de ensino e das falas das professoras.

Segundo Minayo (1998), diferentes são os tipos de análise de conteúdo: de expressão, das relações, de avaliação, de enunciação e categorial temática. Esta última, à qual daremos destaque, se propõe a "descobrir os núcleos de sentido que compõem uma comunicação cuja presença ou frequência signifiquem alguma coisa para o objetivo analítico visado", utilizando-a de forma mais interpretativa, em lugar de realizar inferências estatísticas. A análise categorial temática funciona em etapas, por operações de desmembramento do texto em unidades e em categorias para reagrupamento analítico posterior, e comporta dois momentos: o inventário ou isolamento dos elementos e a classificação ou organização das mensagens a partir dos elementos repartidos.

\subsection{ETAPAS DA ANÁLISE DE CONTEÚDO}

Baseando-nos em Bardin (1988) e em Minayo (1998), sugerimos uma organização dessas etapas para a análise de conteúdo, deixando claro que as intenções e ações a seguir, como vemos no quadro 1, não se apresentam de maneira estanque, linear, e, sim, como um roteiro didático para o tratamento dos dados, sendo importante que o pesquisador tenha ciência de que isso pode passar por entrelaçamentos e, por vezes, idas e vindas. 


\begin{tabular}{|c|c|c|}
\hline ETAPAS & INTENÇÕES & AÇÕES \\
\hline $\begin{array}{l}1^{\text {a }} \text { etapa: } \\
\text { pré-análise }\end{array}$ & $\begin{array}{l}\text { "Retomada do objeto e objetivos da } \\
\text { pesquisa; } \\
\text { "Escolha inicial dos documentos; } \\
\text { *Construção inicial de indicadores para } \\
\text { a análise: definição de unidades de } \\
\text { registro - palavras-chave ou frases; e } \\
\text { de unidade de contexto-delimitação } \\
\text { do contexto (se necessário); }\end{array}$ & $\begin{array}{l}\text { *Leitura flutuante: primeiro contato com os textos, captando } \\
\text { o conteúdo genericamente, sem maiores preocupações } \\
\text { técnicas } \\
\text { *Constituição do corpus: seguir normas de validade: } \\
\text { 1-Exaustividade - dar conta do roteiro; } \\
\text { 2- Representatividade - dar conta do universo pretendido; } \\
\text { 3- Homogeneidade - coerência interna de temas, técnicas } \\
\text { e interlocutores; } \\
\text { 4-Pertinência- adequação ao objeto e objetivos do estudo. }\end{array}$ \\
\hline $\begin{array}{l}2^{\mathrm{a}} \text { etapa: } \\
\text { Exploração } \\
\text { do material }\end{array}$ & $\begin{array}{l}\text { "Referenciação dos índices e a } \\
\text { elaboração de indicadores - } \\
\text { recortes do texto e categorização; } \\
\text { „Preparação e exploração do material - } \\
\text { alinhamento; }\end{array}$ & $\begin{array}{l}\text { *Desmembramento do texto em unidades/categorias - inven- } \\
\text { tário (isolamento dos elementos); } \\
\text { `Reagrupamento por categorias para análise posterior - } \\
\text { classificação (organização das mensagens a partir dos } \\
\text { elementos repartidos) }\end{array}$ \\
\hline $\begin{array}{l}3^{\text {a }} \text { etapa: } \\
\text { Tratamento } \\
\text { dos dados e } \\
\text { interpretação }\end{array}$ & $\begin{array}{l}\text { *Interpretações dos dados brutos } \\
\text { (falantes); } \\
\text { *Estabelecimento de quadros de } \\
\text { resultados, pondo em relevo as } \\
\text { informações fornecidas pelas } \\
\text { análises; }\end{array}$ & $\begin{array}{l}\text { *Inferências com uma abordagem variante/qualitativa, } \\
\text { trabalhando com significações em lugar de } \\
\text { inferências estatísticas. }\end{array}$ \\
\hline
\end{tabular}

Quadro 1 - Roteiro didático para análise de conteúdo

$\mathrm{Na}$ análise de conteúdo, um procedimento importante é a elaboração dos indicadores, como ilustramos, abaixo, no quadro 2. O objeto de estudo da pesquisa precisa ser destacado como elemento central desses indicadores, expressando-se numa temática sintética acerca do que se deseja investigar, como também sua operacionalização, ou seja, como estes se expressarão. No nosso caso, tivemos como foco as informações referentes aos conhecimentos específicos da Educação Física e ao seu movimento na escola como um todo.

\begin{tabular}{l}
\hline Indicadores \\
"Elemento central: trato com o conhecimento - constituição dos saberes escolares; \\
"Operacionalização: tratamento dado ao conteúdo de ensino (seleção, organização e sistematização); \\
"Categorias analíticas: currículo, saberes escolares, cultura escolar; \\
"Categorias empíricas: seleção, organização e sistematização dos saberes escolares; \\
"Pontos de orientação para a investigação, oriundos do objeto de pesquisa - questões gerais
\end{tabular}

Quadro 2 - Indicadores para análise de conteúdo

A categorização evidencia um caminho de ordenação da realidade investigada, na intenção de apreendê-la conceitualmente ${ }^{3}$.

${ }^{3}$ Entendem-se por conceitos os elementos que representam as vigas-mestras de uma construção teórica, ou seja, "as unidades de significação que definem a forma e o conteúdo de uma teoria", podendo os conceitos ser considerados como "operações mentais que refletem certo ponto de vista a respeito da realidade, pois focalizam determinados aspectos dos fenômenos, hierarquizando-os. Existe, então, a necessidade de apreendê-los, analisá-los e defini-los como historicamente específicos e socialmente condicionados (MINAYO, 1998, p. 92-93). 
No âmbito da Teoria do Conhecimento, mantendo a coerência com a perspectiva tomada como base para a referida pesquisa em Educação Física escolar, compreendemos o termo categoria como formas que refletem as propriedades/aspectos e as relações/ligações universais da realidade objetiva, caracterizando-se como graus/ estados do desenvolvimento do conhecimento e das práticas sociais, como princípios do método dialético do conhecimento e da transformação orientada pela realidade. As categorias são conclusões retiradas da história do desenvolvimento da ciência e da atividade prática, portanto podem representar o processo histórico do conhecimento, no decorrer do qual o homem penetra, cada vez mais profundamente, no mundo dos fenômenos, podendo apresentar-se como uma forma particular de conceito (CHEPTULIN, 1982).

No âmbito mais instrumental, mas que não se isola (nem poderia) da Teoria do Conhecimento, observamos o uso de dois grupos de categorias": as analíticas e as empíricas.

As primeiras são aquelas que retêm historicamente as relações sociais fundamentais e podem ser consideradas balizas para o conhecimento do objeto nos seus aspectos gerais. Elas mesmas comportam vários graus de abstração, generalização e de aproximação. As segundas são aquelas construídas com finalidade operacional, visando ao trabalho de campo (a fase empírica) ou a partir do trabalho de campo. Elas têm a propriedade de conseguir apreender as determinações e as especificidades que se expressam na realidade empírica (MINAYO, 1998, p. 94).

Currículo, saberes escolares e cultura escolar foram delimitados como categorias analíticas para, além de colaborar no amadurecimento do objeto e na delimitação do problema, orientar os estudos bibliográficos e de campo.

\footnotetext{
${ }^{4}$ Aqui, numa tentativa de dar um suporte aplicativo aos procedimentos, às técnicas e aos instrumentos, o termo categoria é também entendido como "rubricas ou classes, as quais reúnem um grupo de elementos [...] sob um título genérico, agrupamento esse efetuado em razão dos caracteres comuns desses elementos" (BARDIN, 1988, p. 117).
}

Wovimento, Porto Alegre, v. 16, n. 03, p. 31-49, julho/setembro de 2010. 
Essas categorias analíticas, delimitadas enquanto palavraschave, traduzem os pilares da e para a reflexão conceitual, tanto no trato com a literatura quanto no contato com os dados de campo.

No campo empírico, foram delimitadas categorias empíricas a seleção, organização e sistematização dos saberes escolares, como unidades de codificação que respondem a um movimento dos dados do campo em relação às categorias analíticas. Como veremos, estas sintetizam unidades de contexto e de registro que apreendem a dinâmica do objeto de estudo na realidade empírica.

Unidade de contexto contribui para a compreensão de sentidos a fim de codificar as unidades de registro que, agrupando-as, thes atribui um sentido engajado, ou seja, corresponde ao segmento da mensagem que, pela dimensão superior, propicia entender $\mathrm{o}$ significado de registro (BARDIN, 1988, p. 107).

Unidade de registro é uma unidade de significação a ser codificada e corresponde ao menor segmento de conteúdo a ser considerado como unidade de base, visando à categorização, podendo ser de natureza e dimensões variadas (BARDIN, 1988, p. 104-105).

É necessário, como vemos no quadro 3, delimitar unidades de codificação/categorização de registro - palavra, frase, tema, minuto, centímetro quadrado - e de contexto, sendo esta apenas necessária diante da existência de uma ambiguidade de sentido dos elementos codificados. 


\begin{tabular}{|c|c|c|}
\hline \multicolumn{2}{|l|}{ CATEGORIAS } & DISCIPLINA - Professor(a) - Escola \\
\hline \multicolumn{3}{|l|}{ SELEÇÃO } \\
\hline Unidades de Contexto & Unidades de Registro & \\
\hline \multirow[t]{4}{*}{ FONTE } & Proposta pedagógica & \\
\hline & Livro didático & \\
\hline & Formação continuada & \\
\hline & MEC (incluindo PCN) & \\
\hline \multirow[t]{2}{*}{ RELEVÂNCIA } & Uso do conteúdo & \\
\hline & Vestibular & \\
\hline \multirow{6}{*}{$\begin{array}{l}\text { TEORIA } \\
\text { PEDAGÓGICA }\end{array}$} & Concepção de escola & \\
\hline & Concepção de disciplina & \\
\hline & Concepção de professor & \\
\hline & $\begin{array}{l}\text { Formação do professor e uso } \\
\text { das teorias }\end{array}$ & \\
\hline & Concepção de aluno & \\
\hline & Teoria de referência & \\
\hline \multicolumn{3}{|l|}{ ORGANIZAÇÃO } \\
\hline \multirow{4}{*}{$\begin{array}{l}\text { CONDIÇÕES } \\
\text { ESCOLARES }\end{array}$} & Documentação e acompanhamento & \\
\hline & doPlanejamento & \\
\hline & Conhecimento da turma & \\
\hline & $\begin{array}{l}\text { Condições de trabalho } \\
\text { (recursos e instalações) }\end{array}$ & \\
\hline \multirow{5}{*}{$\begin{array}{l}\text { DISPOSIÇÃO DO } \\
\text { CONHECIMENTO }\end{array}$} & Conteúdos da disciplina & \\
\hline & (tipologia e quantidade) & \\
\hline & Tempo para organização & \\
\hline & Séries & \\
\hline & Ciclos & \\
\hline \multicolumn{3}{|l|}{ SISTEMATIZAÇÃO } \\
\hline \multirow{2}{*}{$\begin{array}{l}\text { ASPECTOS } \\
\text { METODOLÓGICOS }\end{array}$} & Métodos e procedimentos & \\
\hline & Princípios metodológicos & \\
\hline \multirow[t]{2}{*}{ AVALIAÇÃO } & Métodos e procedimentos & \\
\hline & Tempo das aprendizagens & \\
\hline
\end{tabular}

Quadro 3 - Identificação das unidades de contexto e de registro das problemáticas específicas

Nesta pesquisa em Educação Física escolar, vimos, na categoria seleção, como as professoras de Educação Física faziam escolhas por determinados saberes, em detrimento de outros. Percebemos, por exemplo, que estas anunciavam diferentes fontes para essa ação pedagógica, o que nos permitiu o reconhecimento de uma unidade de contexto.

Esses anúncios apontavam a proposta pedagógica como importante fonte para a seleção dos saberes escolares, porém com 
níveis de relação diferenciados por parte de cada professora, ora aproximando-se mais dessa fonte, ora distanciando-se. As demais fontes também influenciavam na seleção, por exemplo, as orientações e estudos realizados na formação continuada e as exigências contidas nas políticas educacionais advindas, principalmente, do Ministério da Educação (MEC), particularmente os Parâmetros Curriculares Nacionais (PCNs).

$\mathrm{Na}$ categoria organização, percebemos, os arranjos e a disposição diante das condições escolares. Os tipos e quantidades de conteúdos, o tempo para sua organização, as informações acerca das séries e ciclos, exemplificam unidades de registro que, quando agrupadas, formam a unidade de contexto, disposição do conhecimento. Nesse aspecto, as professoras apontam que se ressentem da ausência do livro didático, pois, conquanto, a proposta pedagógia ofereça organizações acerca dos saberes escolares, ainda faltam detalhes para sua sequenciação, dosagem e hierarquização ao longo do tempo escolar.

A inexistência de livro didático na Educação Física também influenciava a seleção, pois, pela ausência, as professoras indicavam ter interesse por esse tipo de fonte, como ocorre em outras disciplinas, para planejar e realizar sua intervenção pedagógica.

$\mathrm{Na}$ categoria sistematização, reconhecemos como as professoras estabelecem coerência com uma linha de ação metodológica de ensino e avaliativa diante da interação com os alunos. Por exemplo, os aspectos metodológicos, como unidade de contexto, estavam presentes, na fala no formato de diferentes métodos e procedimentos de ensino, assim como distintas formas de compreender e efetivar os princípios pedagógicos para o uso dos métodos. Além de captar a existência de uma diversidade metodológica nas aulas de Educação Física, ficou evidente na fala das professoras um grande lamento, um enorme esforço e, por vezes, também uma descrença ante a precariedade ou inexistência de um ambiente específico de aula, passando este a ser definidor na estruturação da prática pedagógica, pois as condições climáticas de sol e chuva determinavam a estruturação dos saberes escolares. 
Posteriormente, com um inventário, decompusemos o conteúdo das mensagens escritas e transcritas, procurando, pelas categorias analíticas, encontrar uma codificação dos conteúdos, os quais são isolados entre si e, em seguida, classificados, reagrupando os dados diante de uma categorização, conforme vemos exemplificação da literatura no quadro 4 e dos dados das entrevistas nos quadros 5, 6 e 7.

$\mathrm{Na}$ literatura, recorremos aos textos com uma leitura exaustiva do todo, mas focalizando a pertinência do conteúdo perante as categorias analíticas. Assim, foi possível reconhecer, em diferentes autores e obras, aspectos históricos, sociológicos, políticos e pedagógicos nos conceitos e caracterizações funcionais acerca das categorias analíticas.

\begin{tabular}{|l|l|l|}
\hline $\begin{array}{c}\text { Autores } \\
\text { Elemento }\end{array}$ & \multicolumn{1}{|c|}{ Saviani (1995) } & \multicolumn{1}{c|}{ Lopes (1997) } \\
\hline $\begin{array}{c}\text { Saber } \\
\text { escolar }\end{array}$ & $\begin{array}{l}\text {...o saber dosado e seqüenciado para efeitos } \\
\text { de sua transmissão-assimilação no espaço } \\
\text { escolar, ao longo de um tempo determinado, é } \\
\text { oque nós convencionamos chamar de"saber } \\
\text { escolar" (p. 23). }\end{array}$ & $\begin{array}{l}\text {..o conhecimento escolar se constitui no embate } \\
\text { com os diversos saberes sociais. A escola esco } \\
\text { lar, ao longo de um tempo determinado, seleciona } \\
\text { saberes, dentre os que são passíveis é o que nós } \\
\text { convencionamos chamar de de serem seleciona } \\
\text { dos da cultura social mais "saber escolar" (p. 23). } \\
\text { ampla, e promove sua reorganização, sua rees- } \\
\text { truturação e sua recontextualização. É através } \\
\text { desses processos que emergem configurações } \\
\text { cognitivas tipicamente escolares, compondo uma } \\
\text { cultura escolar sui generis, com marcas capazes } \\
\text { de transcender os limites da escola (p. 106). }\end{array}$ \\
\hline
\end{tabular}

Quadro 4 - Trecho de análise de conteúdo da literatura - exemplo em currículo

Nas entrevistas, exploramos os sentidos e, a partir da fala de cada sujeito, focalizamos os elementos referentes às categorias analíticas e ao objeto de estudo como um todo. Construímos uma legenda para identificação desses conteúdos, como vemos no quadro 5. 


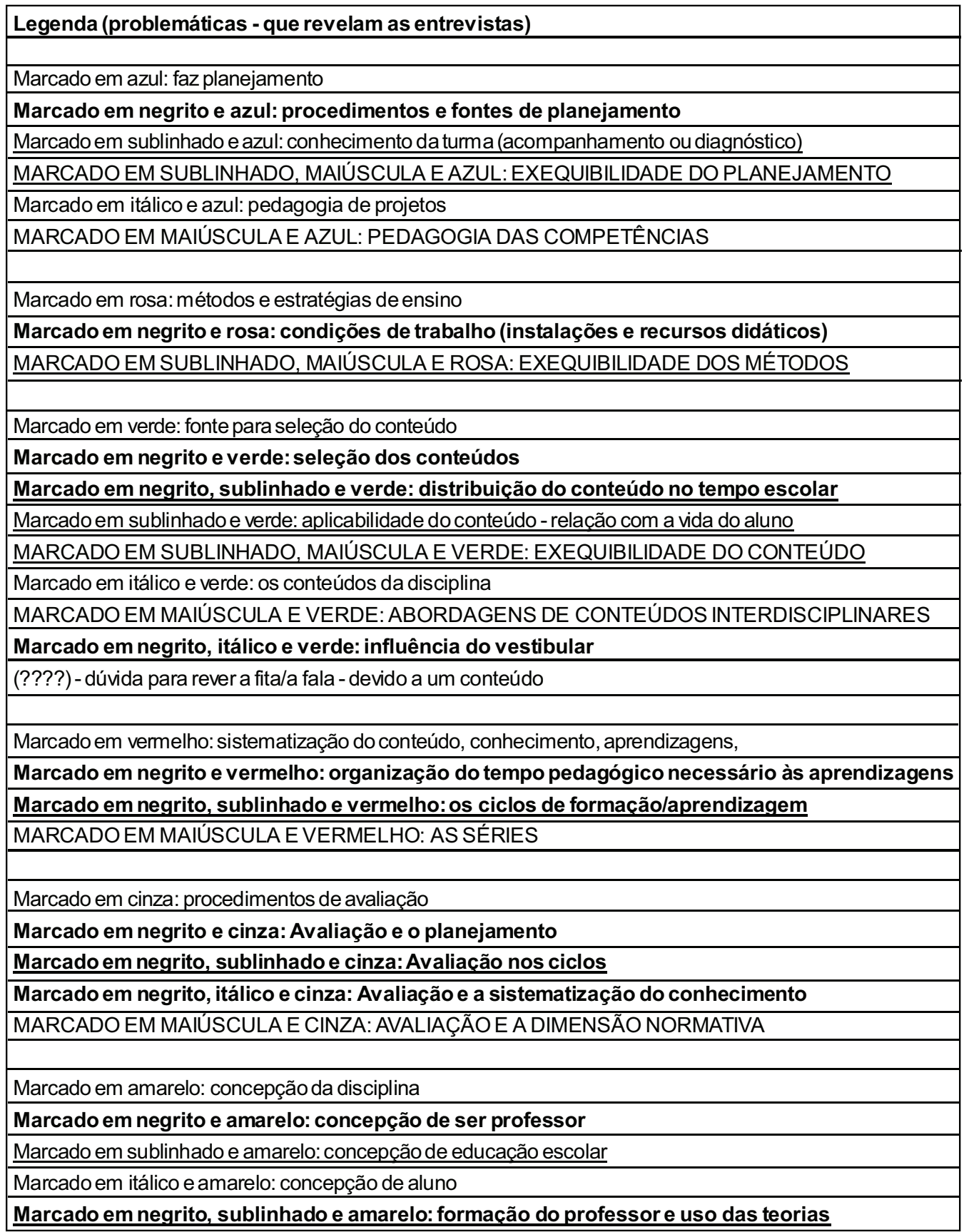

Quadro 5 - Legenda para análise de conteúdo - problemáticas

Conforme podemos observar na legenda da análise de conteúdo, as mensagens transcritas das falas dos sujeitos entrevistados foram organizadas esteticamente, usando formatações e recursos de mudança de cores do Programa Word para Windows XP (Cor da 
fonte e Realce) ${ }^{5}$. Após o processo de transcrição das entrevistas, de checagens das transcrições, de leitura exaustiva, localizamos e deixamos visíveis as perguntas, as respostas e as problemáticas de estudos, como indica o quadro 6.

\begin{tabular}{|c|c|}
\hline $1^{\text {a }}$ entrevista realizada & $6^{a}$ entrevista realizada \\
\hline $\begin{array}{l}\text { Data: } 1 \text { l } \\
\text { Entrevistador: Pesquisador } \\
\text { Entrevistada: Professora de Educação Físi- } \\
\text { ca } 1 \text { - PEF1 } \\
\text { FITA } 01 \text { - LADO "B" } \\
\text { Entrevistador - Onde é que você pega refe- } \\
\text { rências para selecionar esses conteúdos, para } \\
\text { organizar esses conteúdos? } \\
\text { Entrevistada - Eu pego no Coletivo de Auto- } \\
\text { res que falam da questão cultural, né? Minha } \\
\text { base é o coletivo de autores. É o que mais se } \\
\text { adapta. A proposta da Rede. } \\
\text { Entrevistador - Você disse... e essa propos- } \\
\text { ta da Rede também ajuda a você a selecionar } \\
\text { esses conteúdos? } \\
\text { Entrevistada: Ajuda, ajuda. É uma referência } \\
\text { também. Eu também, apesar de que não é } \\
\text { bem aceito aqui na Rede, eu também uso os } \\
\text { PCNs. Eu uso como referência. }\end{array}$ & $\begin{array}{l}\text { Data: } 1 \text { I I } \\
\text { Entrevistador: Pesquisador } \\
\text { Entrevistada: Professor de Educação Física } 2 \\
\text { - PEF2 } \\
\text { FITA 01 - LADO "B" } \\
\text { Entrevistador: Que referência usou pra trazer } \\
\text { esses jogos e não outros? Por exemplo, qual é } \\
\text { o critério? } \\
\text { Entrevistada: Eu acho que o critério principal } \\
\text { que eu vejo é a motivação dos alunos, sabe? } \\
\text { Primeiro, né? Porque antigamente, também, } \\
\text { algumas coisas assim, no basquete não acon- } \\
\text { teceu isso. } \\
\text { Entrevistada: As coisas, a gente discutiu, a } \\
\text { gente achou a necessidade de eles terem esse } \\
\text { conteúdo de basquete. Porque tem bola de } \\
\text { basquete. Entendeu? } \\
\text { Entrevistada: Porque a gente precisa, mesmo } \\
\text { a gente não tendo o arco, mas o Diretor se } \\
\text { esforçou em botar um aí, que mesmo se sepa- } \\
\text { ra, mesmo sem ser oficial. }\end{array}$ \\
\hline
\end{tabular}

Quadro 6 - Trecho de transcrição de Entrevista-identificação de problemáticascategorias empíricas

Elaboramos, com base nas categorias empíricas, quadros a partir de fontes utilizadas, como podemos perceber no quadro 7 . Fizemos uma decomposição/fragmentação de tais dados na forma de tabelas e reagrupamos as categorias empíricas e suas respectivas unidades de contexto e de registro.

\footnotetext{
${ }^{5}$ Optamos aqui por comentar e descrever sobre esse recurso das cores, ao invés de, propriamente, usá-lo. No entanto, essa visualização colorida é um importante recurso para a análise de conteúdo. Nos instrumentos originais de registro das análises, os dados foram organizados a partir da legenda de cores, mas, neste artigo, essa formatação, como exemplificam os quadros 5, 6 e 7, não aparece colorida.
} 


\begin{tabular}{|c|c|c|}
\hline \multicolumn{2}{|c|}{$\begin{array}{l}\text { DISCIPLINAS/Professores } \\
\text { CATEGORIAS }\end{array}$} & Professora de Educação Física 2 - Escola B \\
\hline \multicolumn{2}{|c|}{ SELEÇÃO } & \\
\hline $\begin{array}{l}\text { Unidades } \\
\text { de Contexto }\end{array}$ & $\begin{array}{l}\text { Unidades de } \\
\text { Registro }\end{array}$ & \\
\hline \multirow[t]{4}{*}{ FONTE } & $\begin{array}{l}\text { Proposta } \\
\text { pedagógica }\end{array}$ & $\begin{array}{l}\text { Entrevistador - Onde é que você pega referências para selecionar esses con- } \\
\text { teúdos, para organizar esses conteúdos? } \\
\text { Entrevistada - Eu pego no Coletivo de Autores que falam da questão cultural, } \\
\text { né? Minha base é o coletivo de autores. É o que mais se adapta. A proposta da } \\
\text { rede. } \\
\text { Entrevistador - Você disse... e essa proposta da rede também ajuda a você a } \\
\text { selecionar esses conteúdos? } \\
\text { Entrevistada - Ajuda, ajuda. É uma referência também. Eu também, apesar de } \\
\text { que não é bem aceito aqui na rede, eu também uso os PCNs. Eu uso como } \\
\text { referência. }\end{array}$ \\
\hline & Livro didático & $\begin{array}{l}\text { Entrevistada - Tá definido, não tem questionamento. Na educação física, tem. } \\
\text { Não tem livro, não tem roteiro, a gente segue pelos PCNs. Que foram montados } \\
\text { por determinadas pessoas. A gente não tem livros didáticos que possam servir } \\
\text { como roteiros. } \\
\text { Entrevistador - Aí, as outras disciplinas têm isso, então? } \\
\text { Entrevistada - Têm isso. Que é o diferencial, as outras disciplinas têm livro } \\
\text { didático, têm uma organização já instituída de conteúdos, que podem ser } \\
\text { mudados, mas que já foram instituídos, pela tradição, que vem lá da idade } \\
\text { média, que vem lá de não sei onde, do trivio, do quadrivio, que não tinha aquela } \\
\text { coisa? Que vem toda essa formação, essa lógica ocidental, vem daí. E que foi, } \\
\text { continuou, e vem sendo complementado, não é? Educaçãofísica é uma história } \\
\text { recente, sistematização de conhecimentos, para uma determinada ação na } \\
\text { escola. Uma ... }\end{array}$ \\
\hline & $\begin{array}{l}\text { Formação } \\
\text { continuada }\end{array}$ & \\
\hline & $\begin{array}{l}\text { MEC (incluindo } \\
\text { PCN) }\end{array}$ & \\
\hline
\end{tabular}

Quadro 7 - Análise de conteúdo - problemáticas - exemplo de preenchimento

Esse mapeamento, usando a formatação por cores, permitiu, por exemplo, nos quadros 5 e 6, a visualização, em realce verde, de elementos acerca da fonte que as professoras usavam para a seleção dos saberes escolares na Educação Física. Assim como, no quadro 7, a sua decomposição por sujeito específico para focalizar as unidades das categorias empíricas. Percebemos uma diferenciação entre as professoras, demonstrando ora uma aproximação com a proposta como fonte principal, ora um distanciamento, tomando como fonte outra referência, a exemplo da literatura específica da área da Educação Física escolar ou até mesmo cedendo aos desejos pessoais e motivações dos alunos e até as condições materiais para as aulas.

Em seguida, conforme vemos no quadro 8, realizamos interpretações, associando e confrontando as categorias de três formas e preferencialmente na seguinte ordem de análise: 
1- Leitura na verticalidade - associação/confrontação entre as categorias e unidades de cada fonte (sujeito);

2- Leitura na horizontalidade - associação/confrontação de cada categoria e unidade em todas as fontes;

3- Leitura na transversalidade - associação/confrontação entre as categorias e unidades em todas as fontes (sujeitos);

\begin{tabular}{|c|c|c|c|}
\hline & $\begin{array}{l}\text { DISCIPLINAS } \\
\text { Professores }\end{array}$ & $\begin{array}{l}\text { Professora 1- } \\
\text { PEF1 }\end{array}$ & $\begin{array}{l}\text { Professora 2 - } \\
\text { PEF2 }\end{array}$ \\
\hline QUESTÕES & & & \\
\hline & Proposta pedagógica & & \\
\hline & Livro didático & & \\
\hline & Formação continuada & & \\
\hline & MEC (incluindo PCN) & & \\
\hline RELEVÂNCIA & Uso do conteúdo & & \\
\hline & Vestibular & & \\
\hline TEORIA & Concepção de escola & & \\
\hline PEDAGOGICA & Concepção de disciplina & & \\
\hline & Concepção de professor & & \\
\hline & $\begin{array}{l}\text { Formação do professore } \\
\text { uso das teorias }\end{array}$ & & \\
\hline & Concepção de aluno & & \\
\hline & Teoria de referência & & \\
\hline
\end{tabular}

Quadro 8 - Análises interpretativas

Por fim, fizemos as inferências interpretativas na construção de textos descritivos, argumentativos, analíticos, críticos e propositivos, destacando generalidades e particularidades das análises, inserindo as falas na íntegra, articulando-as às referências teóricas e ainda às nossas próprias percepções, procurando dar conta do nosso objeto de estudo, especialmente a partir dos indicadores para a análise de conteúdo, como mostra o exemplo do quadro 9. 
No que se refere à seleção dos saberes escolares, a PEF1, mesmo tendo na proposta pedagógica da Rede o ponto de partida e afirmando ter como base, como concepção teórica norteadora de suas ações o Coletivo de Autores, referencia suas escolhas nos PCNs, pois estes são indicados várias vezes em sua fala.

Eu pego no Coletivo de Autores (1992) que falam da questão cultural. Minha base é o coletivo de autores. É o que mais se adapta à proposta da rede. [...] Eu também, apesar de não ser bem aceito aqui na rede, eu também uso os PCNs. Eu uso como referência (PEF1).

A relação entre a Proposta da Rede e os PCN's se reapresenta na fala da PEF2, pois esta afirmou que, para a seleção dos saberes escolares, também usou uma proposta elaborada na própria escola onde exerce o magistério. Nessa proposta, que organizou o ensino da Educação Física em módulos, já que as aulas da professora estavam inseridas no ensino médio e este se organiza em regime semestral modular, ficam evidentes referências aos PCN's. Tivemos acesso à proposta por parte da própria professora e evidenciamos seu vínculo com os PCN's, tanto nos conteúdos específicos da Educação Física, que organizava em blocos, por exemplo, de conhecimento sobre o corpo, como também nos eixos norteadores das competências e habilidades (representação e comunicação, investigação e compreensão e contextualização sóciocultural). Além de, na bibliografia, os PCN's também serem citados.

Quadro 9 - Trecho de um texto analítico e interpretativo

\section{CONSIDERAÇÕES FINAIS}

As pesquisas científicas, em especial as de abordagem qualitativa, quando analisadas sob a ótica de uma perspectiva quantitativa, são apontadas como carentes de sustentação metodológica e maior legitimidade, pois, muitas vezes, são criticadas por supostas fragilidades. No entanto, devemos alertar que os estudos qualitativos, necessariamente, não seguem os mesmos princípios e procedimentos investigativos da abordagem quantitativa, garantindo sua rigorosidade com o estatuto científico a partir de outra lógica.

Nada nos impede de fazermos uso ou aproximações entre as abordagens, inclusive complementando procedimentos e análises. Entretanto, faz parte do rigor científico a reflexão de qual é a melhor forma de compreender o objeto de investigação e de orientar a coleta e análise dos dados.

Podemos afirmar que, nos estudos acerca da escola, raramente, o conhecimento pode ser obtido por pesquisas estritamente 
experimentais e análises estatísticas. Junto com Gatti (2002), pensamos que esses tipos de pesquisas e análises são possíveis para uma parte dos problemas de investigação, como, por exemplo, os da área das Ciências da Natureza - (Física, Química, Biologia) os quais são passíveis de quantificação. Porém, em alguns objetos de estudos, como as investigações acerca da escola, e nela se insere a Educação Física escolar, isso não é possível, pois certos controles não podem ser aplicados a seres humanos vivos em situações sociais em que estas se processam.

$\mathrm{Na}$ Educação Física, de uma forma geral, e isso influenciou a Educação Física escolar, a produção do conhecimento esteve sob o império de abordagens positivistas, empírico-analíticas, hipotéticodedutivas, transplantadas das Ciências Naturais, levando-a a um distanciamento das investigações na área das Ciências Humanas, particularmente as que investigavam a escola, alinhando-se muitas vezes à saúde biológica, do ponto de vista funcional do indivíduo, e ao esporte, no que concerne à melhoria dos resultados técnicos (MOLINA NETO; TRIVIÑOS, 1999 e SOUZA E SILVA, 1990, 1997, 2005).

Em contrapartida, reconhecemos um aumento das pesquisas com base em abordagens qualitativas, de abordagens fenomenológicas e dialéticas, o que levou a uma busca por critérios de rigor, com vistas à necessidade de seu maior reconhecimento. É certo que isso é fruto de uma história do pensamento científico, de uma tradição investigativa de nossa área, mas é também de uma contínua necessidade, de todo e qualquer campo da ciência, de uma autocrítica acadêmica, com vistas a uma constante vigilância epistemológica.

Alinhando-nos com André (2001), percebemos que uma metodologia adequada, com procedimentos suficientemente descritos e justificados e uma análise densa, criteriosa e que aponte avanços para a área de conhecimento, é um importante critério de rigor e legitimidade científica. 
Assim, com esses exemplos, instrumentos, procedimentos e fundamentos acerca da análise de conteúdo, como forma de tratamento dos dados, acreditamos contribuir com a operacionalização e rigorosidade científica na pesquisa qualitativa em Educação Física escolar, colaborando assim para que consolidemos, cada vez mais, essa abordagem no campo das pesquisas científicas.

A reflexão realizada aqui confirma a metodologia científica, particularmente os procedimentos para análise de dados, como um construto teórico-prático da interação entre pesquisador e dados de pesquisa.

A trajetória, os procedimentos e os instrumentos de investigação também são uma forma de resultado do trabalho investigativo. Por certo sem oferecer respostas ao problema, mas intimamente alinhado a ele e construído a partir dele.

Como vimos, foi possível entender quais e como se expressam as contradições entre limites e possibilidades na constituição dos saberes escolares em Educação Física no currículo da escola de educação básica. A análise de conteúdo, em coerência com o objeto, o problema, os procedimentos de coleta, deixou perceptíveis e comensuráveis os dados, tornando-os passíveis de inferências.

Por fim, acreditamos que é necessário nos debruçarmos, principalmente no âmbito das abordagens qualitativas, numa consolidação da rigorosidade científica das pesquisas em Educação Física escolar. Tanto dando continuidade às reflexões acerca dos vários procedimentos de análise de dados quanto, sobremaneira, aprofundando estudos sobre o significado de fidedignidade e validade dos dados, o impacto e a consequência dos resultados obtidos, a natureza do conhecimento produzido, as problemáticas privilegiadas na área e os critérios de cientificidade, em especial aqueles exigidos pelos órgãos de fomento. 


The Content Analysis as Data Treatment way in
a School Physical Education Qualitative Research
Abstract: Many times, in books and periodicals, the
elucidation of the investigative methodology is less
emphasized, without favoring the data collection
analysis procedures and instruments recognition as
constructor of the researcher elaboration. In this article,
we present a reflection concerning one of the scientific
methodology phases, focalizing the thematic
categorical content analysis as one of the data
treatment ways. We take like example, to discuss and
base the research act, an investigation developed
under the school Physical Education scope, aiming to
collaborate with the researches scientific
rigorousness consolidation in this area.
Keywords: Scientific methodology. Qualitative
research. Content analysis. School Physical Education.

EI Analisis del Contenido como Manera de
Tratamiento de Ios Datos en una Investigación
Cualitativa en Educación Física Escolar
Resumén: Muchas veces, libros y periódicos, ofrecen
pocos énfasis a la eludición de la metodología
investigativa, favorable o no al reconocimiento de los
procedimientos e instrumentos de colección y análisis
de los datos como construcción de elaboración del
investigador. En este artículo, presentamos una
reflexión sobre una de las fases de la metodología
científica, centrándose en el análisis del contenido de
categoría temático como una de las maneras de
tratamiento de los datos. Tenemos como ejemplo, para
discutir y fundamentar el hecho de este trabajo, una
investigación desarrollada en el ámbito de la Educación
Física escolar, con atención de colaborar en la
consolidación del rigor científico de las investigaciones
en esa área.
Palabras-clave: Metodología científica. Investigación
cualitativa.Análisis de contenidos. Educación Física
escolar.

\section{REFERÊNCIAS}

ANDRÉ, Marli. Pesquisa em educação: buscando rigor e qualidade. Cadernos de Pesquisa, São Paulo, n. 113, p. 51-64, jul. 2001.

BARDIN, Laurence. Análise de conteúdo. Lisboa : Edições 70, 1988. 
CHEPTULIN, Alexandre. A dialética materialista: categorias e leis da dialética. São Paulo: Alfa-Omega, 1982.

FORQUIN, Jean-Claude. Escola e cultura: as bases sociais e epistemológicas do conhecimento escolar. Porto Alegre: Artes Médicas, 1993.

GATTI, Bernadete Angelina. A construção da pesquisa em educação no Brasil. Brasília: Plano, 2002.

GOODSON, Ivor F. Currículo: teoria e história. Rio de Janeiro: Vozes, 1995.

LOPES, Alice Casimiro. Conhecimento escolar: processos de seleção cultural e de mediação didática. Educação \& Realidade, Porto Alegre, v. 22, n. 1, p. 95-112, jan./jun. 1997.

MINAYO, Maria Cecília de Souza. O desafio do conhecimento: pesquisa qualitativa em saúde. 5. ed. São Paulo: Hucitec-Abrasco, 1998.

MOLINA NETO, Vicente; TRIVIÑOS, Augusto Silva (Org.). A pesquisa qualitativa na Educação Física: alternativas metodológicas. Porto Alegre: EDUFRGS, 1999.

MOREIRA, Antônio Flávio Barbosa. Currículos e programas no Brasil. Campinas: Papirus, 1995.

SAVIANI, Dermeval. Pedagogia histórico-crítica: primeiras aproximações. Campinas: Autores Associados, 1995.

SILVA, Tomaz Tadeu da. Documentos de identidade: uma introdução às teorias do currículo. Belo Horizonte: Autêntica, 1999.

SOUZA E SILVA, Rossana Valéria de. Mestrados em Educação Física no Brasil: pesquisando suas pesquisas. 1990. Dissertação (Mestrado) - Universidade Federal de Santa Maria. Santa Maria, 1990.

Pesquisa em Educação Física: determinações históricas e implicações epistemológicas. 1997. Tese (Doutorado) - Universidade de Campinas. Campinas, 1997.

. O CBCE e a produção do conhecimento em Educação Física em perspectiva. In FERREIRA NETO, Amarílio (Org.). Leituras da natureza científica do Colégio Brasileiro de Ciências do Esporte. Campinas: Autores Associados, 2005. p. 45-69.

SOUZA JÚNIOR, Marcílio. A constituição dos saberes escolares na educação básica. 2007. Tese (Doutorado) - Universidade Federal de Pernambuco. Recife, 2007. 